\title{
APPROACHES TO STORYTELLING AND NARRATIVE STRUCTURES IN DESTINATION MARKETING
}

\section{Zuzana Kvítková Zdenka Petrů}

https://doi.org//10.20867/tosee.06.28

\begin{abstract}
Purpose - Storytelling is a very actual trend in destinations' promotion. Travel narratives are renowned for the ability to arouse interest in the reader. The stories can be told in a written form, visual form, or in a form of movements (dances, theatre, etc.). Travel narratives can include more detailed information, they evoke emotions and empathy. Empathy has then a positive relation to behavioral intentions. Therefore, storytelling as a concept is more and more adopted by destination marketing organisations (DMOs). The approach and use of the concept can be different. The aim of the paper is to identify the approaches, and structures used by DMOs and to reveal the level of readers' or tourists' involvement in the narratives.

Methodology - The main purpose of research is reached by conducting an empirical study using the qualitative methods of analysis - content analysis, deconstruction of the stories, analyzing the story structure, and comparison of the identified structures with the theory. Quantitative analysis, descriptive statistics and contingency tables are used to analyse the frequency and combinations of storytelling structures and approaches of the DMOs.

Findings - A narrative is the central theme of the communication in $65.12 \%$ of analyzed campaigns. The most used structures are Petal and Hero's Journey. The tourists are the main characters in $55.81 \%$ of the analyzed campaigns. They are also involved in the story creation in $46.51 \%$. The most used communication channel is YouTube; this is valid on all levels of destinations.

Contribution - Storytelling is an important part of destinations' marketing, however, the research usually brings insight from a narrow or specific point of view (e.g., analysis of one platform or in a form of a case study). This research brings a comprehensive view of the narrative structures used for destinations based on empirical research from several destinations and a deep analysis of the content. Keywords: Tourism, Storytelling, Destination, Marketing.
\end{abstract}

\section{INTRODUCTION}

Storytelling, in general, means activities of sharing stories. Historically, it is linked with culture as a means of transferring cultural values, norms, experiences, and knowledge. Each country's/destination's culture has its own stories, which are shared as a means of entertainment, education, and cultural preservation. Stories communicate also moral values (Chaitin 2003). Storytelling is a means for sharing and interpreting experiences and different kinds of knowledge based on experiential learning. It is not only the listener who learns but also the teller who also becomes aware of his/her own unique experiences and their background (Doty 2003). Storytelling taps into existing knowledge and creates bridges both, culturally and motivationally, toward a solution. Modern storytelling has extended itself to presenting history, personal narratives, political commentary, and 
ToSEE - Tourism in Southern and Eastern Europe, Vol. 6, pp. 425-438, 2021.

Z. Kvítková, Z. Petrů: APPROACHES TO STORYTELLING AND NARRATIVE STRUCTURES ...

evolving cultural norms. Contemporary storytelling is also widely used for educational objectives (Birch et al. 1996) and is also becoming popular in business. Managers prefer stories to abstract arguments or statistical measures. Storytelling is increasingly being used in marketing, especially in advertising to attract customers and build their loyalty (Lury 2004). Customers as human beings need to be entertained. It is easier to remember stories than facts. In the digital age the new forms of media create new ways for people to record, express, and consume stories (Drischel 2018). Marketing developments incorporating storytelling include the use of trans-media techniques that originated in the film industry. These new techniques intend to build an environment in which the story can develop. (Jenkins 2010)

Storytelling is also an integral part of tourism. As mentioned in many tourism books (Holloway 2012, Palatkova 2006, Petru 2007), cultural-historical and natural monuments are the basis and prerequisite for the development of tourism in individual destinations. These sights are the motive for trips to these destinations. Most of these places are associated with a certain history, culture, and stories of the inhabitants who lived and still live in these places. Their stories are passed down orally and in writing from generation to generation. These stories are interpreted orally by tourist guides. In written form, they are part of the guide - books. Storytelling is a means of sharing and interpreting experiences, so also the tourists/visitors can share their experiences from different countries/destinations. Currently, these stories are also used for the promotion of countries/destinations. Destination marketing organisations (DMOs) are responsible for destination promotion. These organisations are working at various levels: national, regional, and local. This article focused on the use of stories in the destinations' promotion at different levels and on the use of various storytelling structures.

\section{STORYTELLING}

Storytelling and word-of-mouth have been the characteristics of human history (Patterson et al. 2005). These days, storytelling has been widely used as a means of content marketing of brands in many countries (Pulizzi 2012). There are lots of studies on storytelling regarding products but less regarding destinations.

Storytelling is intensively discussed in the literature. It is very close to word-of-mouth, but the terms are not interchangeable. The terms can overlap and stories can be communicated in an oral form; however, there is a difference between storytelling and word-of-mouth (Delgadillo and Escalas 2004). Whereas word-of-mouth also simply transfers the facts, the storytelling brings a structured narrative, transfers experience, and can communicate emotions. Storytelling has the potential to engage the receivers (Minazzi 2014). According to Akgün et al. (2015), storytelling is a way of describing events with words, in visual form or audio form. The event might be real or imaginary. The term is defined in different ways according to the context (learning, knowledge management, etc.). Akgün's broad definition is suitable for destination marketing, does not limit the narrative sharing to oral form (McDrury and Alterio 2002, Delete 2002) or to a specific type of content. According to Moscardo (2020), recently the use of "story" in tourism practice has grown considerably, and this reflects a growing recognition that stories are a key driver of, and influence on, tourists' cognitions and behaviour. There is an increasing awareness of the value of stories 
ToSEE - Tourism in Southern and Eastern Europe, Vol. 6, pp. 425-438, 2021.

Z. Kvítková, Z. Petrů: APPROACHES TO STORYTELLING AND NARRATIVE STRUCTURES ...

in psychology (Popova 2015), sociology (Polletta et al. 2011), anthropology (Dunn 2017), and in tourism practice, especially in marketing (Woodside 2010).

\subsection{Storytelling in destination marketing}

Tourism destinations are unique units. They have unique characteristics in terms of tourism development conditions, different from other destinations. According to the World Tourism Organization (UNWTO 2019), the destination is a place with attractions and associated tourism facilities and services that the visitor chooses for his visit. The destination has physical and administrative boundaries. These two elements define its management, image, the destination's perception, and its market competition. The World Tourism Organization (UNWTO 2007) and several other authors (Buhalis 2000), define the attractiveness of a tourism destination based on its characteristic components. All these components contribute to the creation of the product of the destination. The most important part of this product is attractions. Attractions represent the primary (original) offer of tourism, which, due to the quantity, quality, and attractiveness, evokes arrivals to a given destination. Attractions are represented by the natural and cultural-historical potential of the destinations and create the foundations of motives for trips to the destination. According to Cho (2000), attractions can be divided into those "must-see" or "must-do". In the global tourism market, all destinations compete in attracting visitors (Ritchie et al. 2003). Different market segments can be attracted to different tourism destinations. The individual segment will choose the destination when they consider the experience of the stay as a special and different from what they have experienced so far.

Many destinations offer standardized product that is, in fact, difficult to differentiate (beautiful views, nature, historical sites, etc.) from other destinations. Therefore, it is necessary to build a strong and emotional brand (Hudson et al. 2017, Morgan and Pritchard 2004). Storytelling in destination marketing along with a strong story can create unique destination value and increase destination attractiveness or attract a new segment (e.g. destinations connected with Game of Thrones). Storytelling enables strategic communication that supports sustainable competitive advantage (Bassano et al. 2019). Therefore, nowadays, storytelling is an important part of destination marketing. All the experiences offered to visitors that are based on the story will allow visitors to identify emotionally with the story and destination. The experience should be based on local culture. The development of the globalization of tourism is also reflected in the change of orientation of visitors: from sights, customs, and culture different from their own, to peculiarities, unusual, strangeness, extraordinary and unknown (Tjostheim et al. 2000). Every destination has something worth seeing - natural beauty, festivals, works of art, etc. For using storytelling in destination marketing is important to find a representative story.

Sharing a story is related to the development of feeling about the destination. A place becomes popularized through the sharing of experience among visitors (Morgan et al. 2004), especially when using influencer marketing. Sharing a story is a process of active exchange between host-created contents and guest-created contents. A representative way of sharing a story is a community created voluntarily by visitors. Most of their activities are online as a club activity service provided by the major portal. Another way of sharing a story is a community created and promoted by a marketing organisation, including the 
ToSEE - Tourism in Southern and Eastern Europe, Vol. 6, pp. 425-438, 2021.

Z. Kvítková, Z. Petrů: APPROACHES TO STORYTELLING AND NARRATIVE STRUCTURES ...

local government or destination marketing organization. Usually, the marketing organisation provides a space to create an online community, often using social networks, or listens to the opinions of visitors through a survey or reviews. Sharing a story can be done through mutual communication between a local destination marketing organisation or residents and visitors. A local destination marketing organisation usually produces promotional materials and operates a website to provide information on the destination. Destination marketing organisations can use storytelling on their websites and in their promotional e-campaigns. Stories are most often told in the form of videos that are posted on various social networks (Kiralova et al. 2013).

The typical ways of communicating and sharing the stories are their website, blog, social networks, and traditional media. Especially social networks are suitable for communicating the narrative and supporting sharing by the users. Facebook is the largest social network with over 2.74 billion monthly active users as of the second quarter of 2020 (Tankovska 2021c). YouTube with 2.29 billion monthly active users, is the second -largest network (Tankovska 2021a). Travel content is on YouTube very favorite; the views of travel-related videos increased $41 \%$ in August and September 2018, compared to 2017 (www.thinkwithgoogle.com). The destination marketing organisations (DMOs), however, are not very successful in search optimizing, as only $2.81 \%$ of the first 10 search results are videos created by a public organization, typically DMO (Kvítková and Plačko 2019). Instagram has 1.22 billion monthly active users, and its visual communication is a suitable tool for sharing the travel content. Thanks to the users' structure, where it is $62.8 \%$ between 18 and 34 years (Tankovska 2021c), Instagram is an up-and-coming platform and is necessary for communication with the young generation.

Minazzi (2014) states that the storytelling is researched from two main points of views: (1) the marketing and management approach - how the storytelling supports promotion and branding, and (2) the receivers (tourists) perspective - how the storytelling influences their decision-making and what is their role in sharing and creating the stories (often in a form of reviews, etc.). This study corresponds with the managerial perspective and researches the behavior of the destinations represented mostly by a destination marketing organization (DMO).

Lund et al. (2018) propose a framework for analysing the social mechanism in social media. This framework provides marketers (DMO) with a new approach for social media branding. Social media users are conceptualized as storytellers, who co-create brands. Marketers (DMO) can utilize technologies to stipulate storytelling.

\subsection{Storytelling structures}

Storytelling is already a well-developed discipline. The novel writers always wanted to succeed with their story and the literature and practice revealed several scenarios that work. There were identified eight basic structures (in some sources called frameworks) as suitable for destination marketing: The Hero's Journey (also called Monomyth), The Mountain, Nested Loops, Sparklines, In Medias Res, Converging Ideas, False Start and Petal (Lindsay 2015). Each structure comes with a different scenario and is suitable for a different purpose and in different situations. The Hero's Journey is a typical structure for movies but is 
ToSEE - Tourism in Southern and Eastern Europe, Vol. 6, pp. 425-438, 2021.

Z. Kvítková, Z. Petrů: APPROACHES TO STORYTELLING AND NARRATIVE STRUCTURES ...

suitable for destinations as well. The hero is an ordinary man or woman, meets and overcomes different obstacles and grows. This structure is used in case of calling to adventurous and challenging activities or bringing new off-the-beaten-path products. The Mountain is a good structure for maintaining attention, building passion, and intensifying emotions. The Nested Loop is used for presenting narratives with more layers, talking to more kinds of target groups, uncovering different levels of the narrative, or accompanying the main narratives with complementary stories. It enables the communication of more complex stories and information. Sparklines brings the tourists (spectators, listeners) to a dream, a new reality, shows the situation from a positive point of view, and brings a contrast to the current situation, the reality. This structure calls for change shows the possibilities and bright future. It supports dreaming and inspires. In Medias Res is a structure starting in the "middle" of the story. Requires explanation, retrospection and is suitable for dramatic stories with unexpected causes or solutions. It grabs the attention and, if well-timed, awakes curiosity. The structure of Converging Ideas can show the planning, the creation of a travel plan, evolution of an idea. A false start is a structure used to talk about mistakes, learning from them. This structure works with a feel of a secure and expectable story, but it is interrupted with an unexpected change. It takes the listeners out of their certainty. Petal is a structure of more narratives concentrated around one central point - a common point of a story. This structure is also used to communicate more narratives connected by a central topic, targeting more audience, and showing diversity (Lindsay 2015, Barnard, 2018).

Figure 1: Storytelling structures created for marketing.

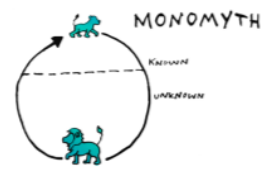

IN MEDIAS RES
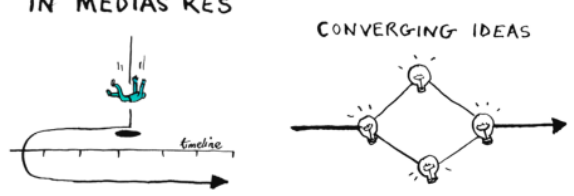

NESTED LOOPS

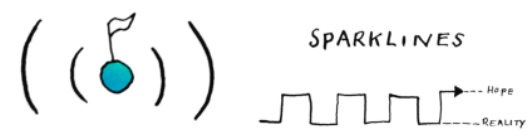

FALSE START

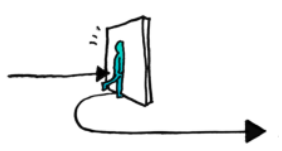

PETAL STRUCTURE

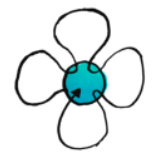

Source: www.sparkol.com

\section{METHODOLOGY AND DATA}

The paper aims to identify the approaches, and structures used by destination marketing organisations, and to reveal the level of readers' or tourists' involvement in the narratives. The main aim of the research is reached by conducting an empirical study using the qualitative methods of analysis. The content analysis, deconstruction of the stories, and analysis of the story structure have been used.

The data were collected from March to April 2021 from 129 campaigns from national, regional, and local destinations. The shares of individual destinations' levels are $36.43 \%$, $40.31 \%$ and $23.26 \%$, respectively. The condition for destination involvement was the usage 
ToSEE - Tourism in Southern and Eastern Europe, Vol. 6, pp. 425-438, 2021.

Z. Kvítková, Z. Petrů: APPROACHES TO STORYTELLING AND NARRATIVE STRUCTURES ...

of storytelling in the campaigns. There was an intention to differentiate the countries according to the economic and tourism development and choose the important players in the tourism market in the regions. The statistical UNWTO division of world tourism into world tourism regions was used. 14 countries from Europe, 4 countries from the American region, 5 countries from the Asian and Pacific region, and 4 countries from the African region were selected. Together 27 countries were selected, four to five campaigns from each were analyzed. The selected countries were analyzed at different destination levels. The data were collected from public sources, mainly social networks (Facebook, YouTube, Instagram, Twitter) and other social media (e.g. blogs). The process of the data collection was the following: identification of the appropriate destination in the region, check of storytelling usage, identification of the campaigns and targeted monitoring of the social media and conduction of a google search with the keywords connected with the campaigns. No automated data collection was used.

In the following paragraphs, the formulated research questions and the corresponding hypothesis are presented.

RQ1: What are the most used story structures in destination marketing?

The main aims of storytelling identified by Eisenloff (2014) are: attracting attention, delivering useful and relevant information, arouse emotions and inspire the imagination of the audience, and consolidating the memory of the tourists. Communication aim is to communicate positively and support the relationship to the destination. For these aims, it is expected that not all the structures are appropriate. Moreover, Akgün et al. (2015) confirms that self-referencing positively influences empathy, and empathy positively increases the word-of-mouth and visit intention. Hero's Journey is expected to enable the identification of the communication receiver with the hero and touch receiver's ego (Herring 2015). Petal is able to show the diversity of the destination, deliver more information and more kinds of beauty, and can talk to more target groups at once (Linday 2015). The Mountain is expected to be appropriate due to the ability to maintain attention and communicate the dynamics, and the destination's atmosphere (Linday, 2015). The Sparklines is expected to be used for its inspirational potential and emotions (Barnard 2018).

Based on the literature, following hypotheses were formulated:

h1: There are story structures that are used more often in destination marketing than the others.

h2: Structures used most are Hero's Journey, Petal, The Mountain, and Sparklines.

RQ2: What is the role of tourists in story creation and communication?

The stories enable the tourists the identification with the hero and destinations. Akgün et al. (2015) confirms the connection between self-referencing, empathy and word-of-mouth. Mattsson and Praesto (2005) argue that local history is a meaningful tool for regional development. It can create local involvement and entrepreneurial spirit. The stories on the local level can be more personalized and authentic, and the relationship can be closer. Therefore, it is expected that the tourist will be more involved in story creation on the local level. The importance of visitors' involvement is emphasized already by Mossberg et al. (2011). The DMOs implementing storytelling into their campaigns work consciously with the latest trends. Therefore, it is expected that if they decide for an active role of the tourists 
ToSEE - Tourism in Southern and Eastern Europe, Vol. 6, pp. 425-438, 2021.

Z. Kvítková, Z. Petrů: APPROACHES TO STORYTELLING AND NARRATIVE STRUCTURES ...

in the creation, they will tend to use the power of word-of-mouth and encourage the tourists to share. The same presumption leads to h6.

Based on the literature, the following hypotheses were formulated:

h3: The tourists are involved in story creation in most campaigns (in more than 50\%).

h4: The destination's level affects tourists' involvement in the story creation and is higher on the local destination level.

h5: The tourists are encouraged to actively share the story more often if they are also involved in the creation.

h6: The tourists are encouraged to actively sharing of the story more often if they are also the heroes.

RQ3: What are the most used platforms for communicating the stories?

Even if the recommendation of friends and relatives usually plays the most important role in the decision-making process, the significance of online platforms and e-WOM (electronic word-of-mouth) is growing. The narratives are shared online in the form of eWOM or as stories created by destinations, influencers, or visitors. The first two hypotheses of this research question are based on the different costs of story creation (mainly presented as video) and communication on different platforms. The recommended length of a video for Facebook is between 2 and 5 minutes (Cucu 2021), so sources recommend ideally up to 90 seconds (Memon 2021). For YouTube, it is 7 to 15 minutes, for Instagram 30 seconds (Memon 2021). As the budget is much higher on the national destination level, bigger projects can be realized, and this leads to hypotheses 7 and 8 . The hypothesis 9 is based on the growing popularity of Instagram, the higher role of visual communication, the higher engagement rate on this platform for tourism (Jipa 2021), and the growing need to reach Gen Y and Z in communication (Turismo 2018, CBI 2021). Molinillo et al. (2018) found that Instagram is a very effective tool for building destination image and create higher intention to visit than Facebook or YouTube.

Based on the literature and sources, the following hypotheses were formulated:

h7: The level of destination affects main used communication platforms.

h8: On the national level, the most used platform is YouTube. On the local level, the most used platform is Instagram.

h9: More often will be used Instagram than Facebook for communicating the stories in general.

Quantitative analysis and descriptive statistics are used to analyze the frequency and combinations of storytelling structures and approaches of the destinations. For confirming or rejecting the hypotheses $\mathrm{h} 4, \mathrm{~h} 5, \mathrm{~h} 6$, and $\mathrm{h} 7$, the analysis of the dependence of two categorical variables, Pearson's statistic G, was used. Cramer's coefficient V was calculated to evaluate the intensity of the dependence.

\section{RESEARCH RESULTS}

129 campaigns from national, regional, and local destinations. The shares of individual destinations' levels are $36.43 \%, 40.31 \%$ and $23.26 \%$, respectively. The analyzed campaigns use storytelling as the main approach, and the story is the central theme of the communication in $65.12 \%$. The other $34.88 \%$ uses stories as an additional and 
ToSEE - Tourism in Southern and Eastern Europe, Vol. 6, pp. 425-438, 2021.

Z. Kvítková, Z. Petrů: APPROACHES TO STORYTELLING AND NARRATIVE STRUCTURES ...

complementary element in communication. The influence of the destination level on the approach to storytelling is shown in Table 1.

Table 1: Distribution of the approach to storytelling on different destination levels, frequency in \%

\begin{tabular}{lcc}
\hline Destination level & Central theme & Additional element \\
\hline National & 82.98 & 17.02 \\
Regional & 50.00 & 50.00 \\
Local & 63.33 & 36.67 \\
\hline
\end{tabular}

Source: own research

With a content analysis and deconstruction of the stories, the RQ1: What are the most used story structures in destination marketing? is answered. The sources distinguish eight different story structures: Hero's Journey, The Mountain, Nested Loops, Sparklines, In Medias Res, Converging Ideas, False Start, and Petal. The result of the content analysis is that destinations use all these structures. However, they do not use them to the same extent (h1 is confirmed). Table 2 presents the results.

Table 2: Used story structures in the destination communication (\%)

\begin{tabular}{lrrr}
\hline Story structure & $\begin{array}{r}\text { Usage of the } \\
\text { structure }\end{array}$ & $\begin{array}{r}\text { In combination } \\
\text { with others }\end{array}$ & Total use \\
\hline Hero's Journey & 20.93 & 12.40 & 33.33 \\
The Mountain & 7.75 & 6.98 & 14.73 \\
Nested Loops & 10.85 & 1.55 & 12.40 \\
Sparklines & 3.88 & 3.10 & 6.98 \\
In Medias Res & 0.78 & 4.65 & 5.43 \\
Converging Ideas & 4.65 & 10.08 & 14.73 \\
False Start & 0.78 & 1.55 & 2.33 \\
Petal & 19.38 & 17.05 & 36.43 \\
\hline
\end{tabular}

Source: own research

The most favorite is the Hero's Journey structure, which is used alone in $20.93 \%$ of the campaigns, shortly followed by Petal, which is used alone in $19.38 \%$. These two structures seem to be very suitable in destination marketing as the other structures follow with great distance - the third one, the Nested loop is used only in $10.85 \%$ of the analyzed campaigns. The campaigns might present the stories in different ways and media, using different scenarios. When analyzing the structures' usage in combination with others, the results bring a similar conclusion - the Petal has used a combination with others in $17.05 \%$ of campaigns, and the Hero's Journey in $12.40 \%$ of campaigns. Structure called Converging ideas is used in combination with others in $10.08 \%$ of the campaigns.

Table 2. also brings an insight into the answer to h2: The most used structures are Hero's Journey, Petal, The Mountain, and Sparklines. These structures are used, however, only the Petal and Hero's Journey are used significantly more than the others. The structures can be grouped into 3 clusters according to the total usage - the most used (Hero's Journey and Petal), less used (The Mountain, Nested Loops, and Converging Ideas), and the least used 
ToSEE - Tourism in Southern and Eastern Europe, Vol. 6, pp. 425-438, 2021.

Z. Kvítková, Z. Petrů: APPROACHES TO STORYTELLING AND NARRATIVE STRUCTURES ...

(Sparklines, In Medias Res, and False Start). There are significant differences in the usage frequency between the three groups: $36 \%-33 \%, 14 \%-12 \%, 2 \%-7 \%$, respectively.

The second research topic is represented by the RQ2: What is the role of tourists in story creation and communication? and the corresponding hypotheses. In $46.51 \%$ of the campaigns, the tourists are involved in the story creation. This result is close to the expectation formulated in $\mathrm{h} 3$, however does not confirm it. Analyzing the involvement in the creation of the story, more than $51 \%$ of tourists are involved in the story on the national $(51.06 \%)$ and regional $(51.92 \%)$ destination level. The local destinations lag in the results; with only $30 \%$ of the campaigns involving the tourists. Based on this result we can reject hypothesis h4: The level of destination has an effect on tourists' involvement in the story creation and is higher on the local destination level. The test criterion Pearson's statistic G (4.29) is a reason for rejection of h4 on the 5\% level of significance. However, it is necessary to mention, that there are only 30 campaigns of local destinations, so the result is rather indicative.

Hypothesis h5: The tourists are encouraged to active sharing of the story more often if they are also involved in the creation is confirmed. The share of campaigns actively encouraging sharing (using hashtags or some calls to share) is $53.33 \%$ among the campaigns co-created by tourists and $31.88 \%$ among the campaigns where the tourists do not participate in the creation. The test criterion Pearson's statistic G 7.60 leads to acceptance of h5 on the 5\% level of significance and confirms the relationship between active involvement in the creation and active encouragement for sharing, even if the intensity of the dependence is rather low $(\mathrm{V}=0.28)$.

The assumption of hypothesis h6: The tourists are encouraged to active sharing of the story more often if they are also the heroes, is also confirmed. In $75.00 \%$ of campaigns using stories, in which tourists play the main role, the sharing is encouraged. Active sharing is supported either by promoting the particular hashtag or by a call for sharing. On the other hand, if the story is not about tourists as the main character of the story, the sharing is actively encouraged in $57.89 \%$. The test criterion Pearson's statistic G 4.24 confirms this hypothesis on a $5 \%$ significance level, even if the intensity of the dependence is low $(\mathrm{V}=0.18)$, the relationship is confirmed.

The confirmation of the hypotheses 5 and 6 leads to the conclusion that the DMOs approach the campaigns systematically and try to get the best from storytelling in respect of communication and visitors' involvement. Involvement of the tourist in any way has a potential to increase their identification with the hero. And as Akgün et al. (2015) proved, that self-referencing positively influences empathy, and empathy positively increases the word-of-mouth.

Even if the tourists play a role in the story in $55.81 \%$ of the analyzed campaigns, the most often heroes are of the stories are the inhabitants of the destination $(64.34 \%)$. A historical character $(10.07 \%)$ and movie character $(6.98 \%)$ were the last types of the heroes analyzed. In some campaigns, there are more main characters in the story.

The third topic of the research was to evaluate the communication platforms used for communicating the stories. This topic is represented by the RQ3: What are the most used platforms for communicating the stories? and the corresponding hypotheses. 
ToSEE - Tourism in Southern and Eastern Europe, Vol. 6, pp. 425-438, 2021.

Z. Kvítková, Z. Petrů: APPROACHES TO STORYTELLING AND NARRATIVE STRUCTURES ...

Table 3: Use of communication channels (\%)

\begin{tabular}{lrrrr}
\hline Communication Channel & $\begin{array}{r}\text { Total } \\
\text { usage }\end{array}$ & $\begin{array}{r}\text { Main } \\
\text { channel }\end{array}$ & $\begin{array}{r}\text { Main or equally } \\
\text { distributed between } \\
\text { more channels }\end{array}$ & $\begin{array}{r}\text { Supportive } \\
\text { channel }\end{array}$ \\
\hline YouTube & 93.80 & 59.69 & 82.17 & 11.63 \\
Instagram & 58.14 & 4.65 & 27.91 & 30.23 \\
Facebook & 58.14 & 8.53 & 31.78 & 26.36 \\
Blog & 27.13 & 9.30 & 24.81 & 2.33 \\
Other channels & 27.13 & 0.00 & 6.98 & 20.16 \\
\hline
\end{tabular}

Source: own research

The analysis reveals that the most used platform is YouTube (used in $93.80 \%$ of the campaigns), followed by Instagram and Facebook (both used in $58.14 \%$ of campaigns). The blog is used in $27.13 \%$ of the campaigns and other channels (Twitter, LinkedIn, own website, TV) to the same extent.

A very different situation is pictured when analyzing the used channels and the way of usage. The position of YouTube as the main communication channel is significantly dominant with $59.69 \%$ in comparison to Blog $(9.30 \%)$, Facebook $(8.53 \%)$, and Instagram $(4.65 \%)$. Considering the campaigns where the channels are equally distributed together with main channels, the position of Facebook and Instagram is better (31.78\% and $27.91 \%$, respectively) in comparison to $82.17 \%$ of campaigns using YouTube. Instagram is used more as a supportive channel (30.23\%).

The main three communication channels analyzed from the destination level's perspective are presented in Table 3. Hypothesis h7: The level of destination that affects main used communication platforms is confirmed. For this test, the cumulative use of channels is calculated (main channel and equally distributed among more channels) because the frequency of Facebook and Instagram as the only main channel is not higher than 5 . The numbers are presented in Table 4.

Table 4: Use of communication channels in different ways and on different destination level (\%)

\begin{tabular}{lcrrr}
\hline Way of usage & Channel & National & Regional & Local \\
\hline Main channel & YouTube & 48,94 & 75,00 & 50,00 \\
& Instagram & 4,26 & 5,77 & 3,33 \\
& Facebook & 2,13 & 11,54 & 13,33 \\
Main or equally distributed & YouTube & 82,98 & 84,62 & 76,67 \\
between more channels & & & & \\
& Instagram & 38,30 & 15,38 & 33,33 \\
& Facebook & 27,66 & 21,15 & 56,67 \\
Supportive channel & YouTube & 10,64 & 13,46 & 10,00 \\
& Instagram & 23,40 & 42,31 & 20,00 \\
& Facebook & 25,53 & 34,62 & 13,33 \\
\hline
\end{tabular}

Source: own research 
ToSEE - Tourism in Southern and Eastern Europe, Vol. 6, pp. 425-438, 2021.

Z. Kvítková, Z. Petrů: APPROACHES TO STORYTELLING AND NARRATIVE STRUCTURES ...

The test criterion Pearson's statistic G 9.84 leads to confirmation of the hypothesis on the $5 \%$ significance level that the destination level plays a role in the communication platforms. The intensity of the dependence is very low $(\mathrm{V}=0.16)$. The indicated difference in the destination levels is between the national and the other levels. The national destinations use more frequently Instagram than Facebook, however, the others use more Facebook than Instagram. Regional and local destinations use the channels in similar ways. The difference is statistically significant when considering the main channel plus equally distributed. If analyzing the total use of the channels, the destinations use similarly regardless of the destination level (test criterion 0.28).

The hypothesis h8: On the national level, the most used platform is YouTube. On the local level, the most used platform is Instagram is not confirmed. Instagram is used more as supportive channel on all levels of destination. YouTube is the most used channel on all destination levels.

The destination marketing focuses a lot on Instagram as the visual way of communication, Instagram Stories as a tool seems to be very suitable for sharing stories. Nevertheless, the hypothesis h9: Instagram will be used more often than Facebook for communicating the stories is not confirmed. In the whole picture, these platforms are used to the same extent. On the regional and local level, Facebook is used even more than Instagram.

\section{CONCLUSION}

The research aimed to identify the approaches, structures used by destination marketing organisations (DMOs), and to reveal the level of readers' or tourists' involvement in the stories. The research was focused on three areas of research - the used structures of the narratives, the role of the tourist in the story and its communication, and the channels used for sharing. A general conclusion can be made that the DMOs using storytelling, use this trend and tool actively, mainly as the main topic of the campaign. The tourists are often the heroes of the story and are involved in the story creation. The structures Petal and Hero's Journey are mostly used and the stories are communicated through YouTube.

A more detailed summary of the results is that the DMOs use the story as the main theme of the campaign in $65.12 \%$, even in $82.98 \%$ in case of the national destinations. The use of the storytelling structures is not even. The structure most used is the Petal and Hero's Journey (total use in $36.43 \%$ and $33.33 \%$ of the campaigns). With a big distance, The Mountain, Converging Ideas and Nested Loops are implemented (in 14.73\%, 14,73\% and $12.40 \%$, respectively). The other frameworks are used only rarely. The tourists play an important role in the stories. They are the main characters in $55.81 \%$ of the analysed campaigns. They are also involved in the story creation in $46.51 \%$ of the campaigns. In case the destination involves the tourists in the story (as co-creators or main characters), the destination encourages also actively the sharing of the stories and experiences. The most used communication channel is YouTube; this is valid on all levels of destination.

Storytelling is an important part of destinations' marketing, however, the research usually brings insight from a narrow or specific point of view (e.g. analysis of one 
ToSEE - Tourism in Southern and Eastern Europe, Vol. 6, pp. 425-438, 2021.

Z. Kvítková, Z. Petrů: APPROACHES TO STORYTELLING AND NARRATIVE STRUCTURES ...

platform or in a form of a case study). This research brings a comprehensive view of the narrative structures used for destinations based on empirical research from several destinations and a deep analysis of the content. The research analyzed 129 campaigns from 27 countries all over the world. It brought an insight into the usage of storytelling in destination marketing. The research confirmed the differences in used narrative structures and the active approach of destinations to storytelling.

As the research analyzes only the practice and does not put the used methods into context with the results, the recommendations for the practitioners are more based on the common practice. The main recommendation is to approach storytelling systematically and actively and use the whole potential of this communication style - involve the tourists in the story as heroes, co-creators, let them feel emotions and identify themselves with the hero, use the tourists as communication media, encourage them to share their experiences and their own stories.

There are certain limitations of the research. The prevailing region is Europe, which is also logic result of its dominant position. This region is dominant in international tourism, both in international arrivals and income. Europe is also important according to the number of countries participating in tourism. The other regions are present to a lower extent. In the research of the communication channels, the accuracy depends on the public visibility of the communication at the time of research, and not $100 \%$ of the channels must have been detected.

Further research direction can go deeper into the managerial decision-making process of the destination managers about incorporating storytelling into their strategies and campaigns. In the future, the research can continue from the visitors' point of view. The questions coming into consideration are: how do the stories affect their decision about visiting the destinations, how does it affect the relationship creation and memorability of the communication. Also, the effect of the national culture on used narratives, for example Asian vs. western culture could play a role.

\section{REFERENCES}

Akgün, A.E., Keskin, H., Ayar, H. and Erdoğan, E. (2015), “The Influence of Storytelling Approach in Travel Writings on Readers' Empathy and Travel Intentions", Procedia - Social and Behavioral Sciences, Vol. 207, pp. 577-586. https://doi.org/10.1016/j.sbspro.2015.10.129

Barnard, D. (2018), How to Tell a Story in a Presentation, viewed 13 September 2021, https://virtualspeech.com/blog/tell-story-delivering-presentation

Bassano, C., Barile, S., Piciocchi, P., Spohrer, J.C., Iandolo, F. and Fisk, R. (2019), "Storytelling about places: Tourism marketing in the digital age", Cities, Vol. 87, pp. 10-20. doi.org/10.1016/j.cities.2018.12.025

Birsh, C., Heckler, M. (1996), Who Says?: Essays on Pivotal Issues in Contemporary Storytelling, August House, Atlanta GA.

Buhalis, D. (2000), Marketing the Competitive Destination of the Future. Tourism Management, 1. Research Polices Practice. Elsevier. https://doi.org/10.1016/S0261-5177(99)00095-3

CBI, Ministry of Foreign Affairs (2021), The European market potential for Generation Y tourism, viewed 13 September 2021, https://www.cbi.eu/market-information/tourism/generation-y-tourism/marketpotential

Cucu, E. (2021), What 3,977,410 Video Posts Tell Us About Facebook Video Strategy In 2021, viewed 13 September 2021, https://www.socialinsider.io/blog/facebook-video-study/ 
ToSEE - Tourism in Southern and Eastern Europe, Vol. 6, pp. 425-438, 2021.

Z. Kvítková, Z. Petrů: APPROACHES TO STORYTELLING AND NARRATIVE STRUCTURES ...

Chaitin, J. (2003), Narratives and Storytelling. Beyond Intractability, in Burgess G. and Burgess H. (Eds.), Conflict Information Consortium, University of Colorado, Boulder. Posted: July 2003 viewed, 10 April 2021, http://www.beyondintractability.org/essay/narratives

Cho, B.H. (2000), Destination, in Jafari, J. (ed.), Encyclopaedia of Tourism, Routledge, London and New York.

Delette , J. (1997), "Using storytelling to teach strategies", The Language resource 1, pp.4-25.

Delgadillo, Y. and Escalas, J.E. (2004), "Narrative word-of-mouth communication: Exploring memory and attitude effects of consumer story-telling”, in Kahn, B.E. and Luce M.F. (Eds.), NA - Advances in Consumer Research, Vol 31, Association for Consumer Research, Valdosta, GA, pp. 186-192.

Doty, E. (2003), Transforming Capabilities: Using Stories for Knowledge Discovery \&Community Development, viewed, 10 April 2021, https://www.storynet.org/wpcontent/uploads/2017/04/DotyTransformingCapabilities.pdf

Drischel, R. (2018), Anthology Storytelling-Storytelling in the Age of the Internet, New Technologies, Artificial Intelligence, viewed 10 April 2021, http://anthologystorytelling.com/

Dunn, C. (2017), "Personal narratives and self-transformation in postindustrial societies", Annual Review of Antropology, Vol. 46, No. 1, pp 248-264.

Eisenloffel, J. (2014). Principles of imagineering - A conceptual framework to enhance virtual experience on tourist websites, in Egger, R. and Maurer C. (Eds.), ISCONTOUR 2014 - Tourism research perspectives, Books on Demand, Norderstedt, Germany, pp. 245-260.

Google.com, Views of travel-related videos increased 41\% in August and September 2018 compared to 2017, YouTube Data, U.S., Aug. 2017-Sept. 2017 and Aug. 2018-Sept. 2018, viewed on 19 May 2021, https://www.thinkwithgoogle.com/consumer-insights/consumer-trends/travel-video-viewstatistics/

Herring, A. (2015), Using the Hero's Journey to Share Your Brand Story. viewed 13 September 2021 https://www.paceco.com/insights/strategy/brand-story-heros-journey/

Holloway, C.J. and Humphreys, C. (2012), The Business of Tourism, (9 th ed.), Person Education Ltd., Harlow, UK.

Hudson, S., Cárdenas, D., Meng, F. and Thal, K. (2017), "Building a place brand from the bottom up", Journal of Vacation Marketing, Vol. 23, No. 4, pp. 365-377.

Jenkins, H. (2010), "Transmedia Storytelling and Entertainment: An annotated syllabus2, Journal of Media\&Cultural Studies, Vol. 24, No. 6, pp. 943-958. https://doi.org/10.1080/10304312.2010.510599

Jipa, A. (2021), Social Media Industry Benchmarks, viewed 13 September 2021, https://www.socialinsider.io/blog/social-media-industry-benchmarks/\#35

Kiralova, A. and Straka, I. (2013), Vliv globalizace na marketing destinace cestovniho ruchu. Ekopress, Praha.

Klear Webpage (2020), The State of Influencer Marketing 2019, viewed 21 November 2020, https://klear.com/TheStateOfInfluencerMarketing2019.pdf. (2019).

Kvítková, Z. and Plačko, M. (2019), „Umí organizace destinačního managementu prosadit svá videa na YouTube?“" (comparative study), Studia Turistica. Vol. 10, No. 3, pp. 36-44. https://www.studiaturistica.cz/wp-content/uploads/2019/04/studia_turistica_2019_3.pdf

Linday, F. (2015), The Seven Pillars of Storytelling, Sparkol Books, Bristol, UK.

Lund, F.N., Cohen, A.S. and Scarles, C. (2018), "The power of social media storytelling in destination branding", Journal of Destination Marketing \&Management, Vol. 8, pp. 271-280.

Lury, G. (2004), Brand Strategy, Issue 182, p. 32.

Mattsson, J. and Praesto, A. (2005), "The Creation of a Swedish Heritage Destination: An Insider's View of Entrepreneurial Marketing",", Scandinavian Journal of Hospitality and Tourism, Vol. 5, No. 2, pp. $152-166$.

McDrury, J. and Alterio, M. (2002), Learning through storytelling in higher education, Kogan Page Limited, Sterling, VA.

Memon, M. (2021), How Long Should a Video Be? Video Length Best Practices, viewed 13 September 2021, https://visme.co/blog/video-length/\#youtube-video-length

Minazzi, R. (2014), Social media marketing in tourism and hospitality, Springer, Berlin.

Morgan, N. and Prichard, A. (2004), Meeting the Destination Branding Challenge, in Morgan N. and Pride R. (eds) Destination branding: creating the unique destination, (2nd ed.)., Elsevier ButterworthHeinemann, Oxford, pp. 59-78.

Mossberg, L., Therkelsen, A., H. Huijbens, E. and Olsson, P. (2011), Storytelling and Destination Development, Nordic Council of Ministers, Copenhagen.

Moscardo, G. (2020), "The story turn in tourism:forces and future”, Journal of Tourism Future, Vol. 7, No. 2, pp. 168-173. https://doi.org/10.1108/JTF-11-2019-0131

Palatkova, M. (2006), Marketingova strategie destinace cestovniho ruchu, Grada Publishing, Praha.

Patterson, A. and Brown, S. (2005), "No Tale, No Sale: A Novel Approach to Marketing Communication", The Marketing Revue, Vol. 5, No. 4, pp. 315-328. https://doi.org/10.1362/146934705775186863 
ToSEE - Tourism in Southern and Eastern Europe, Vol. 6, pp. 425-438, 2021.

Z. Kvítková, Z. Petrů: APPROACHES TO STORYTELLING AND NARRATIVE STRUCTURES ...

Petru, Z. (2007), Zaklady cestovniho ruchu, (2nd ed.), Idea Servis, Praha.

Polletta, F., Chen, P., Gardner, B. and Motes, A. (2011), "The sociology of storytelling", Annual Review of Sociology, Vol.37, No. 1, pp. 109-130.

Popova, Y. (2015), Stories, Meaning and Experience, Routledge, Abingdon.

Pulizzi, J. (2012), "The Rise of Storytelling as the New Marketing", Publishing Research Quarterly, Vol. 28, No. 2, pp. 116-123. https://doi.org/10.1007/s12109-012-9264-5

Ritchie, J.R.B. and Crouch, G.I. (2000), „The Competitive Destination: A Sustainability Perspective“, Tourism Management, Vol. 21, No. 1, pp. 1-7. doi: 10.1079/9780851996646.0000

Tankovska, H. (2021a), Number of monthly active Facebook users worldwide as of 4th quarter 2020, viewed 10 May 2021, https://www.statista.com/statistics/264810/number-of-monthly-active-facebookusers-worldwide/

Tankovska, H. (2021b), Most popular social networks worldwide as of January 2021, ranked by number of active users, viewed 10 May 2021, https://www.statista.com/statistics/264810/number-of-monthlyactive-facebook-users-worldwide/

Tankovska, H. (2021c), Distribution of Instagram users worldwide as of January 2021, by age group, viewed 10 May 2021, https://www.statista.com/statistics/325587/instagram-global-age-group/

Tjostheim, I. and Cohen, E. (2000), What do the Tourists Buy? Marketing and Tourism - a Short Review of Some Articles, Tourism Research, Oslo.

Turismo, Ocio (2018). ¿Cómo viaja la generación Z? [How does generation Z travel?], viewed 13 September 2021, https://www.braintrust-cs.com/como-viaja-la-generacion-z/

Woodside, A. (2010), „Brand-consumer storytelling theory and research“, Psychology and Marketing, Vol 27, No. 6, pp. 531-540.

World Tourism Organization (2007), A Practical Guide to Tourism Destination Management, UNWTO, Madrid, https://www.e-unwto.org/doi/book/10.18111/9789284412433

World Tourism Organization (2019), Tourism Definitions, UNWTO, Madrid. doi:10.18111/9789284420858

Zuzana Kvítková, PhD., Assistant Professor

Department of Tourism, Faculty of International Relations

Prague University of Economics and Business

nám. W. Churchilla 4, 13067 Praha

+420224095264

zuzana.kvitkova@vse.cz

Ing. Zdenka Petrů, Senior Lecturer

Department of Tourism, Faculty of International Relations

Prague University of Economics and Business

nám. W. Churchilla 4, 13067 Praha

+420224095263

zdenka.petru@vse.cz 